\title{
INNOVATIVE MECHANISMS FOR FINANCING MUNICIPALITIES
}

\author{
C 2020 Petrogradskaya Albina Alexandrovna \\ Ph. D., Associate Professor of Theory of Law and Philosophy Department \\ Samara State University of Economics \\ E-mail: petrogradckaya@yandex.ru
} raising.

Keywords: Financing, municipal budget, local government, municipal bonds, book building, fund-

This article is devoted to the study of issues related to the financing of municipalities. The author, in particular, points to the current lack of budget funds for the full implementation of local government authorities. Various mechanisms are used to Supplement local budgets, including the issue of municipal bonds and fundraising.

УДК 342

Код РИНЦ 10.00.00

\section{МЕРЫ ПОДДЕРЖКИ СОЦИАЛЬНОГО ПРЕДПРИНИМАТЕЛЬСТВА}

\author{
() 2020 Преснякова Виктория Владимировна* \\ студент \\ Самарский государственный экономический университет \\ E-mail: presnyakova.vicky@yandex.ru
}

Ключевые слова: социальное предпринимательство, государственная поддержка, социальные проблемы, некоммерческие организации.

В данной статье рассматриваются меры поддержки социального предпринимательства в России. Проведен анализ НПА, регулирующих деятельность предпринимателей, а также меры, способствующие дальнейшему развитию социального предпринимательства.

В настоящее время вопросы распространения социально ориентированных предприятий как одного из эфффективных способов решения общественных проблем включены в политическую повестку многих стран. Все это связано с ростом внимания к вопросам социальной ответственности и переосмыслением роли государства в экономике. Благодаря этому распространение получил не только аутсорсинг государственных программ социальной поддержки и персонализация оказания социальных услуг, но и социально ориентированное инвестирование.

Как известно, цель деятельности предпринимателей состоит в систематическом получении прибыли как от пользования имуществом, так и от продажи товаров и выполнения работ или оказания услуг. Исходя из вышесказанного, цели социального предприятия

\footnotetext{
* Научный руководитель - Паулов Павел Александрович, кандидат юридических наук, доцент.
} 
схожи с целями коммерческих предприятий, но они направлены на "двойственную результативность", поскольку должны включать в себя не только систематическое получение прибыли, но и решение социально-значимых проблем новые или нестандартные бизнесмодели, а также вовлечение дополнительных материальных и нематериальных ресурсов, а главное вся эта деятельность должна быть направленно на уязвимые социально-незащищенные категории населения. ${ }^{6}$

Государственная поддержка социального предпринимательства в России с 2019 года претерпела серьезные изменения. Дело в том, что впервые в законодательство было введено само понятие социального предпринимательства. Соответственно, одновременно закреплены и основные меры поддержки. До 26 июля 2019 года в России отсутствовало единообразие в трактовке понятия "социальное предприятие".

С 26 июля 2019 года в России действует Федеральный закон от 26.07.2019 № 245Ф3, который внес изменения в Ф3 от 24.07.2007 № 209-Ф3 "О развитии малого и среднего предпринимательства в РФ". В данном законе закреплено понятие социальное предпринимательство, которое гласит, что предпринимательская деятельность, является деятельностью направленная непосредственно на достижение общественно полезных целей, способствующая решению социальных проблем граждан и общества и осуществляемая в соответствии с установленными в Федеральном законе № 209-Ф3 условиями. ${ }^{1}$

По сути, данный закон регламентировал на правовом уровне новый вид предпринимательской деятельности, который стал называться социальное предпринимательство. В соответствии с законом № 209-Ф3 социальный предприниматель вправе рассчитывать на финансовую поддержку. При этом под социальным предприятием понимается субъект малого или среднего предпринимательства, осуществляющий деятельность в сфере социального предпринимательства. Федеральный закон № 209-Ф3 перечисляет условия, при соблюдении которых предприятие признается социальным.

Социальным предприятием может быть признан субъект МСП, который отвечает любому из следующих условий: осуществляет виды деятельности, перечисленные в законе № 209-Ф3 (дошкольное и общее образование, дополнительное образование детей, ряд услуг в социальной сфере, выпуск определенной продукции); обеспечивает занятость перечисленных в законе категорий граждан (инвалиды, одинокие и многодетные родители, пенсионеры и другие); обеспечивает реализацию товаров, работ или услуг, которые производятся с участием указанных категорий граждан; оказывает услуги, производит товары или работы, предназначенные для указанных категорий граждан и доля доходов от этой деятельности составляет не менее $50 \%$, и на ее осуществление направляется не менее $50 \%$ чистой прибыли. ${ }^{1}$

Согласно п. 5 ст. 24.1 Закона № 209-Ф3, поддержка социальных предприятий возможна в виде: инфраструктуры поддержки; консультационной и методической поддержки; финансовой поддержки; информационной поддержки; имущественной поддержки; ярмарок, конгрессов, выставок и т.п.; обучения и образования, оценки квалификации. ${ }^{1}$

Для поддержки социального предпринимательства создаются центры инноваций социальной ссреры (ЦИСС), которые предоставляют услуги и консультаций субъектам МСП, а также физическим лицам, желающим начать осуществление социального предпринимательства, кроме того они проводят различные семинары, мастер-классы, тренинги, фрорумы, конференции и круглые столы с участием региональных органов власти, коммерче- 
ских и некоммерческих организаций, поддерживающих социальные проекты. Что касается финансовой и иной поддержки субъектов МСП, то социальные предприятия могут получать меры поддержки субъектов МСП: льготные кредиты по ставке от 8,5 \% до 10,6 \%, гарантии и поручительства, доступ к закупкам крупных компаний, бесплатные онлайн сервисы и др.

Вместе с тем для социальных предприятий разрабатываются также специальные меры поддержки. Так, одной из корпораций были разработаны специальные условия приобретения оборудования по льготному лизингу. В рамках продукта "Микролизинг для развития социального предпринимательства в области здравоохранения и социальных услуг, услуг педагогической направленности" можно приобрести новое оборудование в лизинг по льготной ставке 6\% годовых для российского оборудования или 8\% - для иностранного. Для этого нужно обращаться в региональные лизинговые компании (в любую, независимо от места осуществления деятельности).

Информационно-маркетинговая поддержка субъектов МСП осуществляется в том числе посредством предоставления возможности бесплатно рассчитать примерные бизнес-планы в Бизнес-навигаторе МСП, например:

- Центр раннего развития для дошкольников;

- Кружок детского творчества;

- Танцевальная школа;

- Школа иностранных языков.

Центры инноваций социальной сферы - своего рода институты, осуществляющие разнообразные виды поддержки социальных предпринимателей, такие как: бесплатные консультации по вопросам правового обеспечения бизнеса, маркетинговых стратегий бизнеса, бизнес-планирование, бухгалтерский учет.

В настоящее время Министерство экономического развития целиком и полностью поддерживает политику государственной поддержки социального предпринимательства. Министерство отслеживает объем средств бюджетного финансирования для реализации программ по поддержке социально ориентированного бизнеса.

Некоторые крупные и консалтинговые компании, в рамках своих благотворительных программ предоставляют поддержку социальным предпринимателям оказывая профессиональные услуги, такие как финансовое и юридическое консультирование.

Помимо Федерального закона №209-Ф3, меры поддержки социального предпринимательства могут устанавливаться и в иных НПА, как в федеральных, так и в региональных или местных. Так, в Налоговом кодексе Российской Федерации установлены налоговые льготы для ряда социально-значимых видов деятельности.

Для предприятий, осуществляющих образовательную или медицинскую деятельность, а также для тех, кто предоставляет различные социальные услуги, по налогу на прибыль устанавливается нулевая налоговая ставка. Перечни конкретных видов деятельности утверждены постановлениями Правительства России от 10.11.2011 № 917 и от 26.06.2015 № 638 .

Возможность использования нулевой ставки является таковой, при полном соблюдении условий, перечисленных в Налоговом кодексе РФ. Исходя из условий, прописанных в Налоговом кодексе, доходы составляют не менее $90 \%$ доходов организации, а также в штате организации должно числится не менее 15 работников. Это одни из основных усло- 
вий пользования нулевой ставкой, существуют также и другие условия, они указанные в статьях 284.1 и 284.5 Налогового кодекса. ${ }^{2}$

Крупные компании и деловые объединения также уделяют внимание развитию социального предпринимательства. На протяжении последних нескольких лет ряд компаний крупного бизнеса приступили к организации проектов содействия развитию социального предпринимательства. Такое содействие, как правило, заключается в проведении информационно-просветительских мероприятий, организации обучения предпринимателей, ведущих деятельность в социальной сфере, консультировании и менторстве (наставничестве), проведении инвестиционных сессий, предоставлении возвратного финансирования. В России такой опыт имеют компании СУЭК, Металлоинвест, РУСАЛ, Северсталь, Урановый холдинг АРМЗ, ГМК "Норильский Никель" и другие.7

Этим механизмы поддержки социального предпринимательства не ограничены. Также возможна реализация иных мер и мероприятий, которые предусмотрены федеральными законами, принимаемыми в соответствии с ними иными нормативными правовыми актами, а также законами и актами регионов, муниципальными правовыми актами.

1. Федеральный закон от 24.07.2007 № 245-Ф3 "О развитии малого и среднего предпринимательства в РФ" (в ред. 26.07.2019)

2. "Налоговый кодекс Российской Федерации (часть вторая)" от 05.08.2000 N 117-Ф3 (ред. от 27.12.2019, с изм. от 28.01.2020) (с изм. и доп., вступ. в силу с 28.01.2020)

3. Постановление Правительства РФ от 10.11.2011 N 917 (ред. от 06.03.2015) "Об утверждении перечня видов образовательной и медицинской деятельности, осуществляемой организациями, для применения налоговой ставки 0\% по налогу на прибыль организаций"

4. Постановление Правительства РФ от 26.06.2015 N 638 "Об утверждении перечня социальных услуг по видам социальных услуг, предоставляемых организациями, осуществляющими социальное обслуживание граждан, для применения налоговой ставки 0\% по налогу на прибыль организаций"

5. Паулова Е.О., Паулов П.А. К вопросу о подходах к определению предпринимательского договора // Вестник Волжского университета им. В.Н. Татищева. - 2018. - Т. 1. № 2. - С. 117-122.

6. Social enterprise Market // URL: http://www.socialenterprisemarketing.org/.

7. Центр сертификации социальных предпринимателей // URL: http://www.nbconsult.ru/uslugi/center/.

8. [Электронный ресурс]: учеб. пособие / С.Н. Ревина, П.А. Паулов, Д.В. Борякин, А.В. Сидорова. - Электрон. дан. - Самара : Изд-во Самар. гос. экон. ун-та, 2019.

\section{SOCIAL ENTREPRENEURSHIP SUPPORT MEASURES}

(C) 2020 Presnyakova Victoria Vladimirovna

Student

Samara State University of Economics

E-mail: presnyakova.vicky@yandex.ru

Keywords: social entrepreneurship, state support, social problems, non-profit organizations.

This article discusses measures to support social entrepreneurship in Russia. The analysis of regulatory acts governing the activities of entrepreneurs, as well as measures conducive to the further development of social entrepreneurship, has been carried out. 